\title{
Dependence of Vickers Hardness on Layer Thickness in Electrodeposited Ni-Co-Cu/ Cu Multilayered Films
}

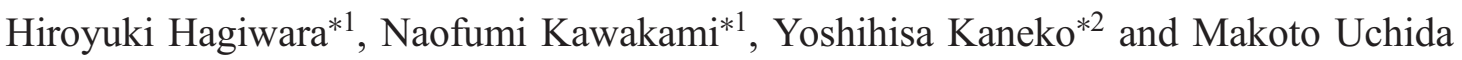 \\ Department of Mechanical Engineering, Osaka City University, Osaka 558-8585, Japan
}

The layer thickness dependence of Vickers hardness was investigated in $\mathrm{Ni}-\mathrm{Co}-\mathrm{Cu} / \mathrm{Cu}$ multilayered films having layer thicknesses $h$ ranging from $10 \mathrm{~nm}$ to $300 \mathrm{~nm}$. The $\mathrm{Ni}-\mathrm{Co}-\mathrm{Cu} / \mathrm{Cu}$ multilayered films were fabricated by electrodeposition. In the layer thickness range of $h \geq 75 \mathrm{~nm}$, the hardness increased with decreasing layer thickness. Conversely, the hardness decreased with decreasing layer thickness at $h \leq 75 \mathrm{~nm}$. At $h=10 \mathrm{~nm}$, the hardness decreased to $97 \mathrm{HV}$, although the local maximum at $h=75 \mathrm{~nm}$ was $210 \mathrm{HV}$. In the X-ray diffraction (XRD) profiles around the fcc (111) peak, the $10 \mathrm{~nm}$ multilayered film revealed a single peak, while two peaks corresponding to the Ni-Co-Cu and $\mathrm{Cu}$ layers were detected in the other multilayered films. The low hardness of the $10 \mathrm{~nm}$ film can be understood from the absence of interface strengthening, which was deduced from the single XRD peak. For $20 \mathrm{~nm} \leq h \leq 75 \mathrm{~nm}$, the two (111) peaks approached each other. The decreased hardness in this region could be related to sparse misfit dislocations, which can be estimated from the XRD peak angles. [doi:10.2320/matertrans.MT-M2019165]

(Received June 14, 2019; Accepted September 13, 2019; Published October 21, 2019)

Keywords: multilayered film, nanostructured material, electrodeposition, hardness

\section{Introduction}

Fine grains produced by plastic work such as equal channel angular pressing typically show an equiaxed shape ${ }^{1,2)}$ by which three-dimensional grain refinement is achieved. Metallic materials with such equiaxed fine grains usually exhibit high strength because dislocation glides are impeded by highly-densified grain boundaries. Similar strengthening has also been found in multilayered composites that are composed of alternating stacks of dissimilar metallic layers. High tensile strength, ${ }^{3-8)}$ hardness, ${ }^{9-18)}$ and wear resistance $^{19-21)}$ have been attained in several kinds of multilayered films. One could say that multilayers are strengthened by a one-dimensional fine-grained structure. Recently, such a layered structure has received attention in research on the long-period stacking ordered (LPSO) phase of $\mathrm{Mg}-\mathrm{Zn}$-based alloys. ${ }^{22-24)}$ The LPSO structure can also be categorized as a multilayered structure consisting of soft and hard thin layers. Accordingly, multilayer structuring is a potent route to obtaining a high-strength material.

One of the key factors that determine the strength of a multilayered structure is the component layer thickness. The layer thickness dependence of the tensile strength ${ }^{3-6,8)}$ and the hardness ${ }^{9-15,17,18)}$ has been studied for several kinds of multilayered films. Basically, the strength of a multilayered structure, which is estimated by tensile deformation and hardness experiments, increases with decreasing layer thickness. This tendency is analogous to that established in a coarse-grained polycrystalline material where the strength increases with decreasing grain size in accordance with the Hall-Petch relation. The microscopic strengthening process in multilayered structures has been attributed to the dislocation pile-up at the interfaces (Hall-Petch model) and the glide resistance of dislocations inside the confined layers (Orowan model), where the critical shear stress increases with decreasing layer thickness in both models. ${ }^{25)}$ However,

\footnotetext{
${ }^{* 1}$ Graduate Student, Osaka City University

${ }^{* 2}$ Corresponding author, E-mail: kaneko@eng.osaka-cu.ac.jp
}

in the $\mathrm{Ni} / \mathrm{Cu},{ }^{3,4,9,10,14)} \mathrm{Ni} / \mathrm{Ag},{ }^{12)}$ and $\mathrm{Cu} / \mathrm{Nb}^{15)}$ multilayers, the strength was lower in thin layer thicknesses, which is inconsistent with the above models. The reason for this strength lowering is still unclear.

For further improvement in multilayered structures, it seems reasonable to employ a highly-alloyed layer instead of a soft pure metal layer. One feasible pair is $\mathrm{Ni}-\mathrm{Co}-\mathrm{Cu} / \mathrm{Cu}$ layers, which can also be obtained by the electrodeposition technique. For electrodeposited $\mathrm{Ni}-\mathrm{Co}-\mathrm{Cu} / \mathrm{Cu}$ multilayered films, studies have been conducted on the fabrication method, ${ }^{26-28)}$ microstructures, ${ }^{29,30)}$ and giant magnetic resistance (GMR) ${ }^{31,32)}$ However, the layer thickness dependence of strength has not been reported yet. In the present study, the authors prepared $\mathrm{Ni}-\mathrm{Co}-\mathrm{Cu} / \mathrm{Cu}$ multilayered films having various layer thicknesses. Vickers hardness measurements and X-ray diffraction (XRD) analyses were carried out. In particular, we discussed the hardness lowering in thin layer thickness regions by considering the possible microstructures as deduced from the XRD profiles.

\section{Experimental Procedure}

$\mathrm{Ni}-\mathrm{Co}-\mathrm{Cu} / \mathrm{Cu}$ multilayered films were deposited on polycrystalline copper plates having dimensions of $20 \times$ $15 \times 3 \mathrm{~mm}^{3}$. Before the electrodepositions, the copper substrates were annealed at $973 \mathrm{~K}$ for $1 \mathrm{~h}$ in a vacuum. The copper substrates were then mechanically and electrolytically polished. The surfaces of the substrates were insulated by lacquer except for a circular area of $9 \mathrm{~mm}$ diameter. Multilayered films were electrodeposited on the circular area. The multilayered films deposited on the copper substrates were used for hardness tests and cross-sectional observation. In addition to the copper substrates, platinum plates were used for energy dispersive spectroscopy (EDS) and XRD analyses.

An aqueous solution containing nickel sulfamate, cobalt sulfate, and copper sulfate was used for electrodeposition. Details of the solution composition are listed in Table 1. During electrodeposition with an electrolyte that contains 
Table 1 Composition of the electrolyte for electrodepositing the $\mathrm{Ni}-\mathrm{Co}-$ $\mathrm{Cu} / \mathrm{Cu}$ multilayered film.

\begin{tabular}{cc} 
Component & Concentration \\
$\mathrm{Ni}\left(\mathrm{SO}_{3} \mathrm{NH}_{2}\right)_{2} \cdot 4 \mathrm{H}_{2} \mathrm{O}$ & 403.6 \\
$\mathrm{CoSO}_{4} \cdot 7 \mathrm{H}_{2} \mathrm{O}$ & 70.3 \\
$\mathrm{CuSO}_{4} \cdot 5 \mathrm{H}_{2} \mathrm{O}$ & 2.5 \\
$\mathrm{H}_{3} \mathrm{BO}_{3}$ & 31 \\
$\mathrm{C}_{7} \mathrm{H}_{5} \mathrm{NO}_{3} \mathrm{~S}_{(\mathrm{Saccharin})}$ & 0.05 \\
$\mathrm{NaC}_{12} \mathrm{H}_{25} \mathrm{SO}_{4}(\mathrm{SDS})$ & 0.025 \\
\hline
\end{tabular}

several ions having different ionization tendencies, the chemical composition of a deposit depends on the applied potential. Hence, we controlled the deposit composition using these electrolytes: copper was deposited at a low cathodic potential, while $\mathrm{Ni}-\mathrm{Co}-\mathrm{Cu}$ alloy was deposited at a high cathodic potential. In the present study, the $\mathrm{Cu}$ and the $\mathrm{Ni}$ $\mathrm{Co}-\mathrm{Cu}$ layers were deposited at -400 and $-1600 \mathrm{mV}$, vs standard hydrogen electrode (SHE), respectively.

The electrodeposition current was supplied by the Hokuto Denko HA151 potentiostat, to which a computer was connected. By applying two different potentials alternately, we fabricated the $\mathrm{Ni}-\mathrm{Co}-\mathrm{Cu} / \mathrm{Cu}$ multilayers on the substrates. The thickness of a deposited layer was calculated instantaneously by monitoring the electric charge consumed during the electrodeposition. For the $\mathrm{Cu}$ layer deposition, when the consumed electric charge became a preset value, the potential was switched from -400 to $-1600 \mathrm{mV}$ vs SHE. The similar process was conducted for the $\mathrm{Ni}-\mathrm{Co}-\mathrm{Cu}$ layer, where the potential was switched from -1600 to $-400 \mathrm{mV}$ vs SHE at the end of the layer deposition. The ratio of the $\mathrm{Ni}-\mathrm{Co}-\mathrm{Cu}$ layer thickness to that of $\mathrm{Cu}$ was $1: 1$, and each layer thickness ranged from $10 \mathrm{~nm}$ to $300 \mathrm{~nm}$. The total thickness of the multilayered films was approximately $3 \mu \mathrm{m}$. For comparative purposes, we prepared $\mathrm{Ni}-\mathrm{Co}-\mathrm{Cu}$ alloys and copper deposits that were grown under a constant potential of -1600 and $-400 \mathrm{mV}$ vs SHE, respectively.
EDS analysis with the JEOL JSM-6500F scanning electron microscope (SEM) was conducted on the $\mathrm{Ni}-\mathrm{Co}-\mathrm{Cu}$ alloy and $\mathrm{Cu}$ deposits obtained under the constant potentials. Cross sections of the multilayered films were also observed using the SEM. Before cross sectioning, the surfaces of the electrodeposited films were covered with a thick copper film, which was additionally electrodeposited. The multilayered films were cut perpendicular to their surface, and then the cross sections were mechanically polished. To identify the component layers by SEM observation, the cross sections were etched.

The hardness tests were carried out using the Shimadzu DUH-W201 tester. The indentation force was $10 \mathrm{mN}$. For each sample, hardness measurements were taken 10 times. The hardnesses of $\mathrm{Ni}-\mathrm{Co}-\mathrm{Cu} / \mathrm{Cu}$ multilayered films were measured under the condition that the films were not removed from the copper substrates. The microstructures of the $\mathrm{Ni}-\mathrm{Co}-\mathrm{Cu} / \mathrm{Cu}$ multilayered films were investigated by XRD analyses in the Rigaku RINT-2200PC, where a Co-K $\alpha$ $\mathrm{X}$-ray was used.

\section{Results}

\subsection{Multilayered structures}

We first conducted EDS analyses on homogeneous films that were electrodeposited at constant potentials. The chemical composition of the film grown at $-1600 \mathrm{mV}$ vs SHE was $\mathrm{Ni}-30$ at $\% \mathrm{Co}-3$ at $\% \mathrm{Cu}$, and almost pure copper was obtained at $-400 \mathrm{mV}$ vs SHE. Figure 1 shows SEM images of the cross sections of the $\mathrm{Ni}-\mathrm{Co}-\mathrm{Cu} / \mathrm{Cu}$ multilayered film. Because the cross sections were etched, the $\mathrm{Ni}-\mathrm{Co}-\mathrm{Cu}$ layers are visible as bright horizontal lines. The dark lines between them correspond to the copper layers. Figure 1(a) shows the multilayered film where the target layer thickness was $h=20 \mathrm{~nm}$. Due to the etching, the very thin $\mathrm{Ni}-\mathrm{Co}-\mathrm{Cu}$ layers seemed to deform, and thus we could not quantify the individual layer thickness by SEM observation. The cross section shown in Fig. 1(b) is the multilayered film of $h=100 \mathrm{~nm}$. The individual $\mathrm{Ni}-\mathrm{Co}-\mathrm{Cu}$ and $\mathrm{Cu}$ layers are clearly visible, and the measured average layer thickness was approximately $100 \mathrm{~nm}$; we successfully electrodeposited multilayered film with the preset target layer thickness. Hence, in the present study, we refer to the preset target layer thickness as the component layer thickness.
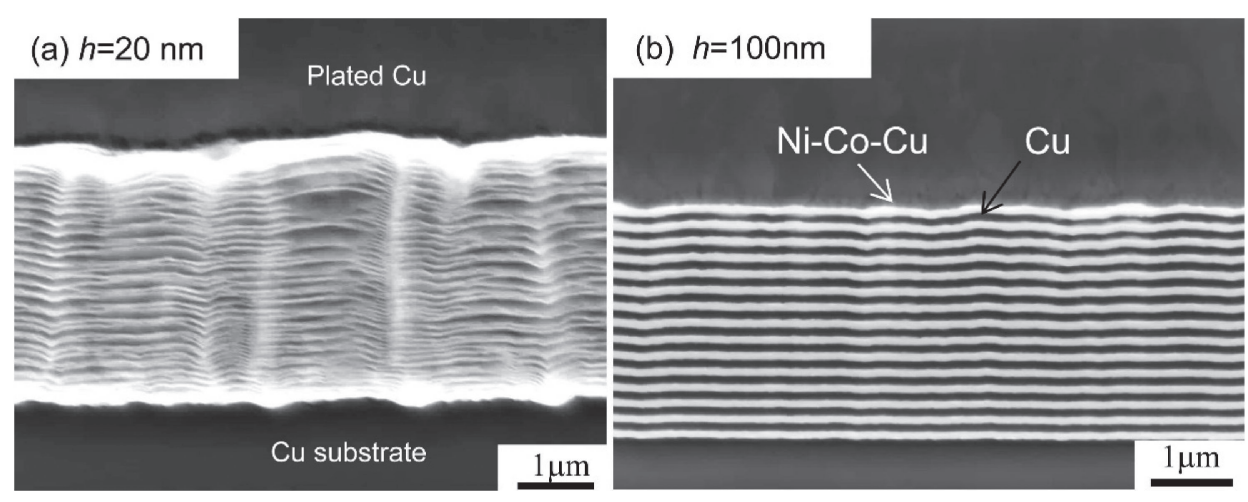

Fig. 1 Cross sections of the Ni-Co-Cu/Cu multilayered films having layer thicknesses of (a) $h=20 \mathrm{~nm}$, and (b) $h=100 \mathrm{~nm}$. 


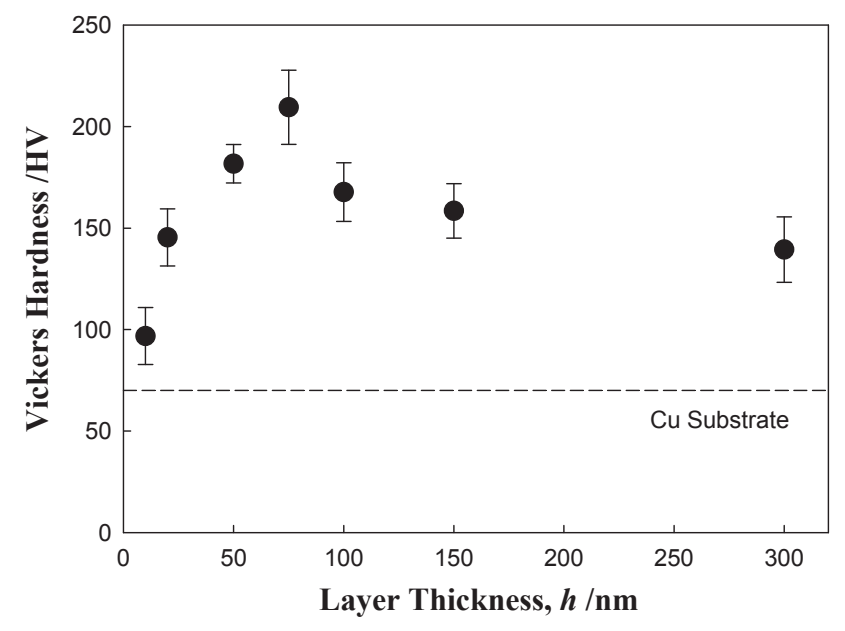

Fig. 2 Dependence of the Vickers hardness on the component layer thickness of the $\mathrm{Ni}-\mathrm{Co}-\mathrm{Cu} / \mathrm{Cu}$ multilayered films.

\subsection{Vickers hardness}

Figure 2 shows the relationship between the Vickers hardness and the component layer thickness of the $\mathrm{Ni}-\mathrm{Co}-$ $\mathrm{Cu} / \mathrm{Cu}$ multilayered films. The hardness of the copper substrate is also indicated in the figure as a dotted line, and is approximately $50 \mathrm{HV}$. Because the hardness tests were conducted under the condition that the multilayered films were on the soft copper substrates and the film thicknesses were only $3 \mu \mathrm{m}$, the measured hardness would be reduced by the soft substrates. It is hence noted that we treated the measured hardnesses as relative strengths in the present study. For the multilayered films of $h \geq 75 \mathrm{~nm}$, the hardness increased with decreasing layer thickness. It was confirmed that the thinning of the component layer certainly led to strengthening in the electrodeposited $\mathrm{Ni}-\mathrm{Co}-$ $\mathrm{Cu} / \mathrm{Cu}$ multilayered films. In contrast, at a layer thickness of $h \leq 75 \mathrm{~nm}$, the hardness decreased with decreasing layer thickness. The hardness at $h=10 \mathrm{~nm}$ was reduced to $97 \mathrm{HV}$, while the hardness at the local maximum $(h=75 \mathrm{~nm})$ was $210 \mathrm{HV}$.

We first consider the layer thickness dependence at $75 \mathrm{~nm} \leq h \leq 300 \mathrm{~nm}$. The hardness of multilayered films has been argued mainly on the basis of the Hall-Petch and Orowan models, ${ }^{24)}$ as described in the introduction. The Hall-Petch model for a multilayered structure assumes dislocation pile-up at interfaces formed between component layers. In this model, the strength of a multilayered film is proportional to the reciprocal of the square root of the layer thickness $\left(h^{-1 / 2}\right)$. The Orowan model puts a hairpin-shaped dislocation inside a confined layer that is sandwiched by two interfaces. The stress required to glide the bowing dislocation is proportional to the reciprocal of the layer thickness $\left(h^{-1}\right)$. Figure 3 shows the Vickers hardness plotted against the $h^{-1 / 2}$ and the $h^{-1}$ values for $75 \mathrm{~nm} \leq h \leq 300 \mathrm{~nm}$. The hardness increases with both $h^{-1 / 2}$ and $h^{-1}$ values. The squared determination coefficient $r^{2}$ of each relation is also indicated in the figure: the $r^{2}$ values are 0.872 and 0.917 for the $h^{-1 / 2}$ and $h^{-1}$ values, respectively. There is no significant difference between them, but the $h^{-1}$ values proposed in the Orowan model gives a better fit than the $h^{-1 / 2}$ values.

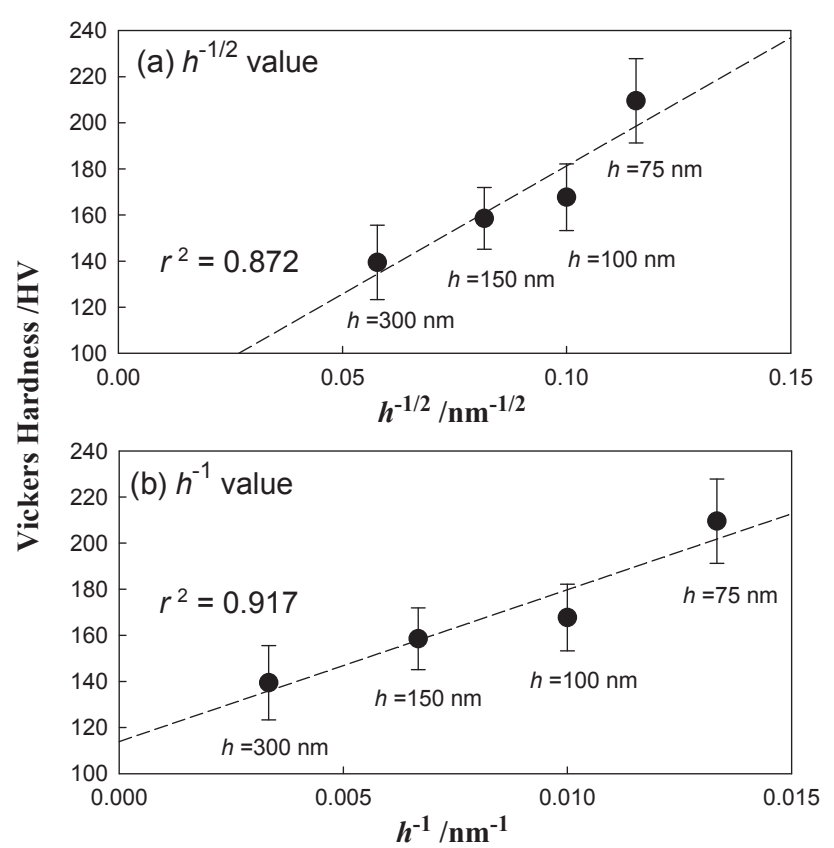

Fig. 3 Vickers hardness plotted against the $h^{-1 / 2}$ and $h^{-1}$ values for $75 \mathrm{~nm} \leq h \leq 300 \mathrm{~nm}$.

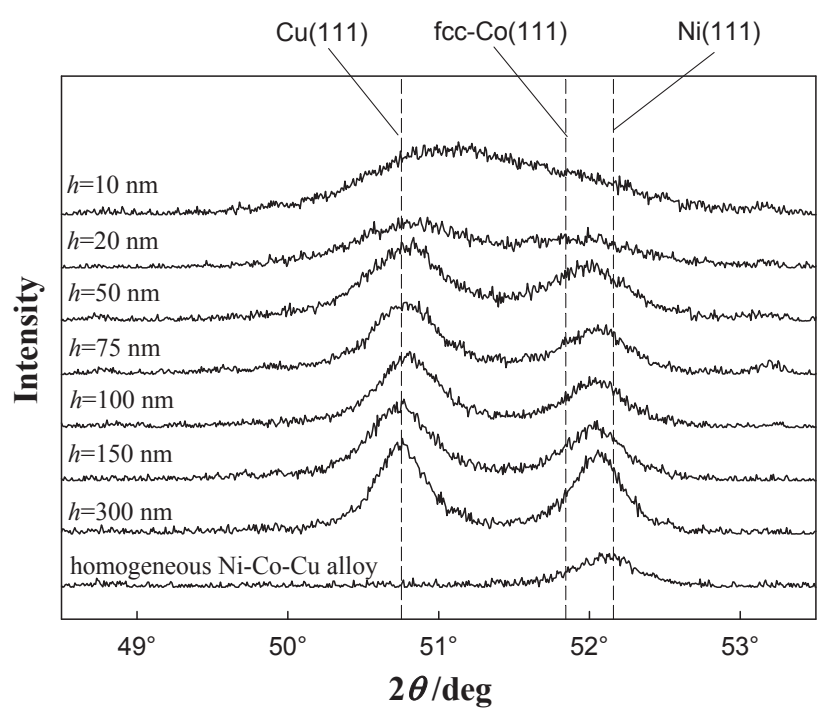

Fig. 4 XRD profiles of the $\mathrm{Ni}-\mathrm{Co}-\mathrm{Cu} / \mathrm{Cu}$ multilayered films having various layer thicknesses around the fcc (111) peak angles.

\subsection{XRD analyses}

The XRD profiles measured in the angular range of $49^{\circ}<2 \theta<53^{\circ}$ are presented in Fig. 4. The positions of the ideal (111) diffraction peaks for copper, fcc-cobalt, and nickel are indicated by the dotted lines in the figure. All the detectable diffraction peaks of the multilayered films were from fcc structures, even though the Co content of the Ni$\mathrm{Co}-\mathrm{Cu}$ layer amounted to $30 \mathrm{at} \%$. In the present study, the $\mathrm{Ni}-\mathrm{Co}-\mathrm{Cu}$ layer is referred to as being an fcc single-phase material. In addition, the profile of the $\mathrm{Ni}-\mathrm{Co}-\mathrm{Cu}$ alloy film deposited under constant potential is indicated, and a single (111) diffraction peak can be recognized. This single peak, of course, is consistent with the constant applied potential that would produce a homogeneous microstructure throughout the film. 
In the XRD profiles of each multilayered film, except for the $h=10 \mathrm{~nm}$ layer thickness, two diffraction peaks appeared. These two peaks were the diffractions at both the $\mathrm{Ni}-\mathrm{Co}-\mathrm{Cu}$ and $\mathrm{Cu}$ layers, which have different lattice constants. Because it was almost coincident with the ideal $\mathrm{Cu}$ (111) diffraction angle, the peak at the small angle was from the $\mathrm{Cu}$ layers. The other peak at the large angle, which was between the fcc-Co and $\mathrm{Ni}$ (111) peak angles, should be from the $\mathrm{Ni}-\mathrm{Co}-\mathrm{Cu}$ layers. However, at $h=10 \mathrm{~nm}$, a single XRD peak was detected. This result suggests that the lattice constant of the $10 \mathrm{~nm}$ multilayered film was not separated into two values, despite the different potentials were applied alternately during the electrodeposition.

\section{Discussion}

\subsection{Multilayered film having $10 \mathrm{~nm}$ layer thickness}

The authors considered two possible microstructures to account for the single XRD peak at $h=10 \mathrm{~nm}$. One is a simple alloy structure without layer stacking. It is feasible that the desired multilayered structure was not constructed because the target layer thickness was too thin. In this case, the absence of the $\mathrm{Ni}-\mathrm{Co}-\mathrm{Cu} / \mathrm{Cu}$ interfaces can result in the low hardness measured at $h=10 \mathrm{~nm}$ (Fig. 2).

The other possibility is the configuration of the coherent interfaces: the component layers had the same lattice constant, although a layered atomic distribution was certainly constructed. In our previous study on annealing of the electrodeposited $\mathrm{Ni} / \mathrm{Cu}$ multilayered films, ${ }^{33)}$ the as-deposited film having a layer thickness of $5 \mathrm{~nm}$ revealed a single XRD peak, as did the $10 \mathrm{~nm}$ multilayered film in the present study. However, after the annealing at $573 \mathrm{~K}$, new additional $\mathrm{XRD}$ peaks corresponding to the respective component layers emerged. This behavior can be explained by the annihilation of coherent interfaces. Low-temperature annealing can promote local accommodation near the interfaces, resulting in the emergence of an XRD peak from the accommodated lattices having intrinsic lattice constants. Such coherent interfaces have also been reported in electrodeposited $\mathrm{Ni} / \mathrm{Cu}$ multilayered film where the layer thickness was less than $10 \mathrm{~nm} .{ }^{34)}$ Accordingly, the coherent interface model is applicable to the present $\mathrm{Ni}-\mathrm{Co}-\mathrm{Cu} / \mathrm{Cu}$ multilayered film of $h=10 \mathrm{~nm}$, and its low hardness is attributable to the easy dislocation passage across the coherent interfaces.

\subsection{XRD peak angles}

In the transmission electron microscope (TEM) observations of the electrodeposited $\mathrm{Ni}-\mathrm{Co}-\mathrm{Cu} / \mathrm{Cu}$ multilayered films, ${ }^{29)}$ the electron diffraction patterns were typical for a single crystal. This result suggests that the stacking layers grew epitaxially. When different fcc lattices are adjoined in the same orientation, misfit dislocations are introduced geometrically at their interfaces to accommodate lattice mismatch. If the present $\mathrm{Ni}-\mathrm{Co}-\mathrm{Cu} / \mathrm{Cu}$ multilayers are also stacked by means of epitaxial growth, misfit dislocations must exist at the interfaces.

For the multilayered films of $h \geq 20 \mathrm{~nm}$, two (111) peaks appeared as mentioned above. Moreover, it was notable that the respective positions of the two peaks depended on the layer thickness. Figure 5 shows the peak angles plotted

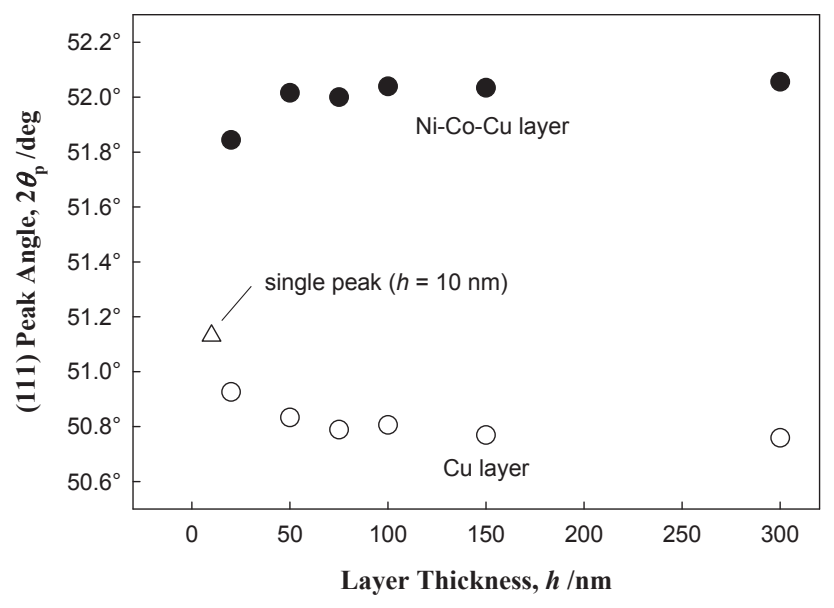

Fig. 5 XRD peak angles of the fcc (111) diffraction plotted against the layer thickness.

against the layer thickness. For $h=10 \mathrm{~nm}$, the angle of the single peak is plotted. The peak angles of the $\mathrm{Cu}$ layers were almost invariable in the layer thickness range of $50 \mathrm{~nm} \leq$ $h \leq 300 \mathrm{~nm}$. When the thickness was reduced to $h=20 \mathrm{~nm}$, the peak angle became apparently larger. On the contrary, for the $\mathrm{Ni}-\mathrm{Co}-\mathrm{Cu}$ layers, the peak angle decreased with decreasing layer thickness in the thin layer thickness range, while the peak angles of $h \geq 75 \mathrm{~nm}$ were invariable. Hence, in the thin layer thickness region, the lattice constant of each component layer deviated from its intrinsic lattice constant. The lattice constant of the $\mathrm{Ni}-\mathrm{Co}-\mathrm{Cu}$ layer seemed to approach that of the $\mathrm{Cu}$ layer, as the layer thickness became thinner.

To understand the unusual lattice constants in the thin layer region, the authors presume that an interface maintains coherent structure immediately after the applied potential is switched to the other potential during the electrodeposition process. In the case of the coherent interface, the lattice mismatch should be relaxed by the in-plane elastic strain of the component layers. When a growing deposit is only a few atomic layers thick, the elastic strain of the growing deposit can be energetically favorable, in comparison with the production of misfit dislocations. Thus, one can expect that the complete set of misfit dislocations is not introduced instantaneously at the potential switch, but that the misfit dislocations are gradually introduced as the deposit grows. In this electrodeposition model, a change in the lattice constant requires a certain amount of growth. When the component layers are very thin, the lattice constants of both layers eventually become close to each other. This microstructural model can explain the result that the XRD peak angle difference was small for the thin layer thickness (Fig. 5).

\subsection{Misfit dislocation model}

Figure 6 is a two-dimensional misfit dislocation model consisting of two adjoining lattices. For simplification, the misfit dislocations of edge character are regularly arranged along the interface. Both lattices have the same orientation but differ in their lattice constant. In Fig. 6, the upper part with the short lattice constant corresponds to the $\mathrm{Ni}-\mathrm{Co}-\mathrm{Cu}$ layer of the present study. The lower part is the $\mathrm{Cu}$ layer. The 


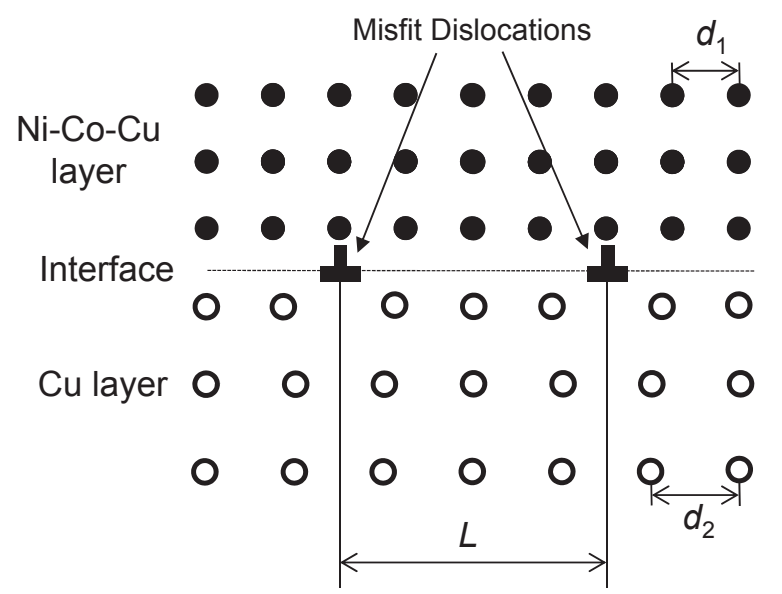

Fig. 6 Two-dimensional model of misfit dislocations between the $\mathrm{Ni}-\mathrm{Co}-$ $\mathrm{Cu}$ and the $\mathrm{Cu}$ layers.

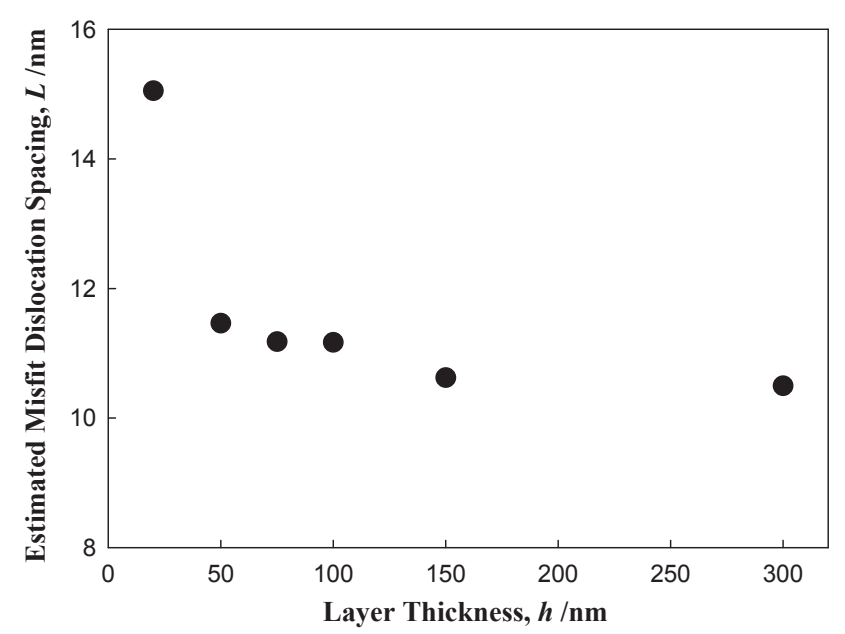

Fig. 7 Misfit dislocation spacing estimated from the (111) peak angles of the $\mathrm{Ni}-\mathrm{Co}-\mathrm{Cu}$ and $\mathrm{Cu}$ layers.

misfit dislocations are positioned with regular spacing $L$, given by the following equation.

$$
L=\frac{d_{1}{ }^{2}}{d_{2}-d_{1}}
$$

where $d_{1}$ and $d_{2}$ are the interplanar spacings of the upper and lower lattices. In the present study, we employ the Burgers vectors $b_{1}$ and $b_{2}$ as the respective interplanar spacings. We obtained the interplanar spacings from the (111) peak angles shown in Fig. 5, on the basis of Bragg's diffraction condition. The average spacings $L$ were estimated from eq. (1) by substituting the Burgers vectors as the interplanar spacings. Figure 7 shows the relationship between the estimated misfit dislocation spacing $L$ and the layer thickness $h$. Because no double (111) peak was detected at $h=10 \mathrm{~nm}$, the dislocation spacing of this sample is not plotted. In the thin layer thickness region, the estimated misfit dislocation spacing increased with decreasing layer thickness, although the thick layer thickness region exhibited an almost constant value of approximately $10 \mathrm{~nm}$. At $h=20 \mathrm{~nm}$, the misfit dislocation spacing exceeded $15 \mathrm{~nm}$.

\subsection{Multilayered films of $20 \mathrm{~nm} \leq \boldsymbol{h} \leq 75 \mathrm{~nm}$}

Figure 8(a) shows the relationship between the hardness

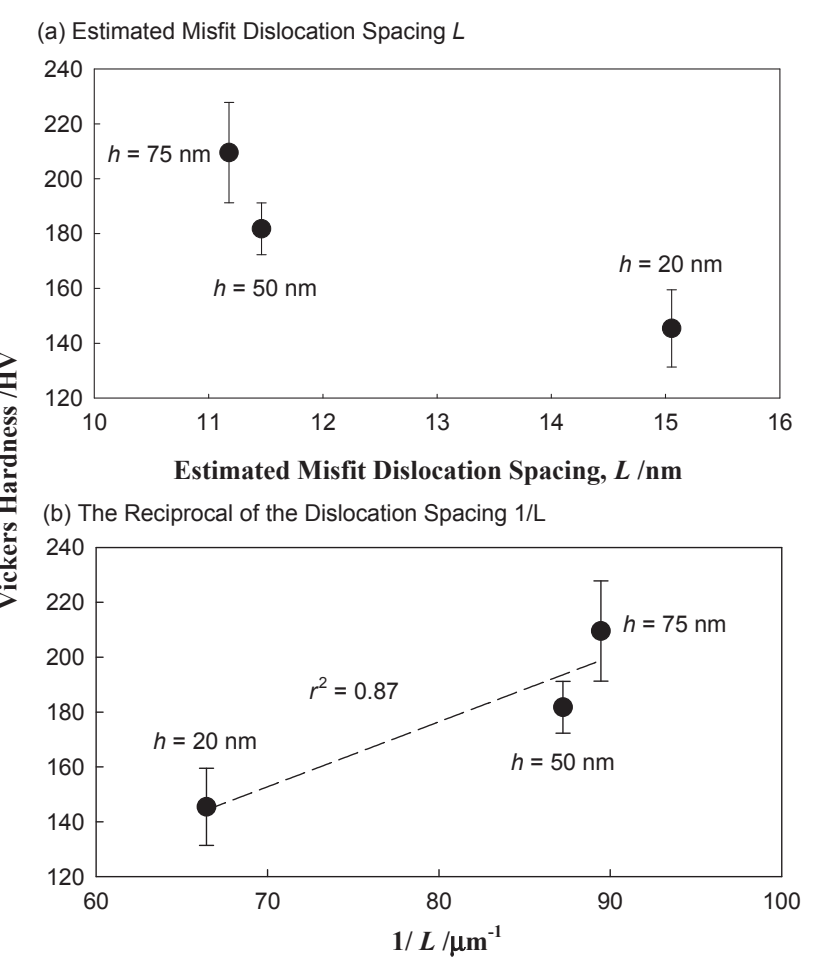

Fig. 8 Vickers hardness plotted against (a) the estimated misfit dislocation spacing $L$, and (b) the reciprocal of the dislocation spacing $1 / L$ for the layer thickness range of $20 \mathrm{~nm} \leq h \leq 75 \mathrm{~nm}$.

and the estimated misfit dislocation spacing for $20 \mathrm{~nm} \leq$ $h \leq 75 \mathrm{~nm}$, where the hardness decreased with decreasing layer thickness. The hardness also decreased with increasing dislocation spacing. This result strongly suggests that that the misfit dislocation arrangement can contribute to the hardness. The relationship between the misfit dislocation density and the hardness has also been noted in $\mathrm{Ag} / \mathrm{Ni}$ multilayers prepared by magnetron sputtering. ${ }^{12)}$

Let us consider a dislocation glide that is impeded by obstacles. In this case, the critical shear stress is determined principally by the strength of the obstacles and the average spacing between the obstacles. For the obstacles arranged as a square grid array, the critical shear stress $\tau_{\mathrm{c}}$ at which the mobile dislocation overcomes the obstacles is as follows: ${ }^{35)}$

$$
\tau_{\mathrm{c}}=\frac{\mu b}{l} \cos \left(\frac{\phi}{2}\right)
$$

where $\mu$ is the shear modulus, $\phi$ is the breakaway critical angle between the pinned dislocation segments, and $l$ is the spacing between obstacles. The obstacle strength is incorporated in the critical angle $\phi$. According to eq. (2), the critical shear stress is proportional to the reciprocal of obstacle spacing $l^{-1}$. For the $\mathrm{Ni}-\mathrm{Co}-\mathrm{Cu} / \mathrm{Cu}$ multilayered films, the misfit dislocations existing at the interfaces can act as the obstacles to the mobile dislocations. Hence, the authors treated the misfit dislocation spacing $L$ as the obstacle spacing $l$. Figure 8(b) shows the hardness re-plotted against the reciprocal of the misfit dislocation spacing $L^{-1}$. The hardness increases with increasing $L^{-1}$ values but seems to deviate somewhat from a linear function $\left(r^{2}=0.87\right)$ if the authors estimate from three plots. The details of the deviation are still unclear, but we deduced that the hardness in the thin 
layer thickness region was determined by several factors. For example, because the hardness increased with decreasing layer thickness for $75 \mathrm{~nm} \leq h \leq 300 \mathrm{~nm}$, it is reasonable to think that the hardness should be enhanced even at a much thinner layer thickness. Hence, in addition to the interface strength coming from the misfit dislocations, the layer thickness may play an important role on the hardness in the thin layer thickness region.

As reviewed in the introduction, the strengths of the $\mathrm{Ni}$ / $\mathrm{Cu}^{3,4,9,10,14)}$ and the $\mathrm{Ag} / \mathrm{Ni}^{12)}$ multilayered structures were lower for the thin layer thicknesses. By contrast, no strength reductions in the thin layer were found in the $\mathrm{Cu} / \mathrm{Cr}^{10}$ ) and the $\mathrm{Cu} / \mathrm{Ag}^{13)}$ multilayered structures. For the $\mathrm{Cu} / \mathrm{Nb}$ layers, ${ }^{10,15)}$ both cases were reported. Hence, the occurrence of strength reduction in a thin layer may depend on a combination of component metallic materials. Because both the $\mathrm{Ni}$ and $\mathrm{Cu}$ have fcc lattices, it is probable that the interfaces in a $\mathrm{Ni} / \mathrm{Cu}$ multilayer have a semi-coherent structure and misfit dislocations. Thus, the misfit dislocation model is also applicable to the $\mathrm{Ni} / \mathrm{Cu}$ multilayered structure, which revealed strength reductions in the thin layer regions. However, in the $\mathrm{Ni} / \mathrm{Cu}$ multilayers, the layer thicknesses at peak strength ranged from 5 to $20 \mathrm{~nm}$, while the peak hardness was attained at $h=75 \mathrm{~nm}$ in the present study.

To consider this difference, the authors gave attention to the lattice mismatch between component layers. When the lattice mismatch is small, one can expect misfit dislocations produced during layer growth to be sparse. The lattice mismatch of the $\mathrm{Ni}-\mathrm{Co}-\mathrm{Cu} / \mathrm{Cu}$ multilayered film was $2.3 \%$, which was estimated from the XRD peaks at $h=300 \mathrm{~nm}$. This value is smaller than that in the $\mathrm{Ni} / \mathrm{Cu}$ pair $(2.6 \%)$. Hence, the production of a misfit dislocation during deposition could be infrequent in the $\mathrm{Ni}-\mathrm{Co}-\mathrm{Cu} / \mathrm{Cu}$ multilayered films. If misfit dislocations are gradually produced from an interface as discussed above, the production rate of misfit dislocations should affect the minimum layer thickness at which the lattice mismatch is fully accommodated by the misfit dislocations; the $\mathrm{Ni}-\mathrm{Co}-\mathrm{Cu} / \mathrm{Cu}$ multilayered film may require a wider layer thickness to achieve the full accommodation. Accordingly, the smaller lattice mismatch in the $\mathrm{Ni}-\mathrm{Co}-\mathrm{Cu} / \mathrm{Cu}$ multilayered films can attribute to the peak hardness at $h=75 \mathrm{~nm}$, which was wider than those of the $\mathrm{Ni} / \mathrm{Cu}$ multilayered films.

\section{Conclusion}

(1) The Vickers hardness of the $\mathrm{Ni}-\mathrm{Co}-\mathrm{Cu} / \mathrm{Cu}$ multilayered films electrodeposited on the copper substrates depended on the component layer thickness $h$. For the layer thickness range of $h \geq 75 \mathrm{~nm}$, the hardness increased with decreasing layer thickness. On the contrary, the hardness decreased with decreasing layer thickness for $h \leq 75 \mathrm{~nm}$.

(2) In the XRD profiles of the multilayered films of $h \geq 20 \mathrm{~nm}$, two (111) peaks from the $\mathrm{Ni}-\mathrm{Co}-\mathrm{Cu}$ and $\mathrm{Cu}$ layers were detected. However, the multilayered film of $h=10 \mathrm{~nm}$ revealed a single XRD peak. The low hardness of $h=10 \mathrm{~nm}$ could be attributed to the absence of interface strengthening, which was deduced from a single XRD peak.
(3) In the thin layer region, both (111) XRD peaks deviated from the intrinsic angles corresponding to those of the thick layer region. As the layer thickness became thinner, the two peaks approached each other. It is proposed that, except for the $10 \mathrm{~nm}$ film, the hardness in the thin layer region was affected by the sparse misfit dislocations that were estimated from the two peak angles.

\section{Acknowledgments}

This study was supported by JSPS KAKENHI for Scientific Research in Innovative Areas "MFS Materials Science" (Grant Number 18H05483), and JSPS KAKENHI for Scientific Research (C) (Grant Number 19K05034).

\section{REFERENCES}

1) Y. Iwahashi, Z. Horita, M. Nemoto and T.G. Langdon: Acta Mater. 46 (1998) 3317-3331.

2) R.Z. Valiev, R.K. Islamgaliev and I.V. Alexandrov: Prog. Mater. Sci. 45 (2000) 103-189.

3) S. Menezes and D.P. Anderson: J. Electrochem. Soc. 137 (1990) 440444.

4) D.M. Tench and J.T. White: J. Electrochem. Soc. 138 (1991) 37573758 .

5) D. Josell, D. van Heerden, D. Read, J. Bonevich and D. Shechtman: J. Mater. Res. 13 (1998) 2902-2909.

6) H. Huang and F. Spaepen: Acta Mater. 48 (2000) 3261-3269.

7) N. Mara, A. Sergueeva, A. Misra and A.K. Mukherjee: Scr. Mater. 50 (2004) 803-806.

8) J.Y. Zhang, X. Zhang, R.H. Wang, S.Y. Lei, P. Zhang, J.J. Niu, G. Liu, G.J. Zhang and J. Sun: Acta Mater. 59 (2011) 7368-7379.

9) R.R. Oberle and R.C. Cammarata: Scr. Metall. Mater. 32 (1995) 583588.

10) A. Misra, M. Verdier, Y.C. Lu, H. Kung, T.E. Mitchell, M. Nastasi and J.D. Embury: Scr. Mater. 39 (1998) 555-560.

11) R.C. Cammarata, T.E. Schlesinger, C. Kim, S.B. Qadri and A.S. Edelstein: Appl. Phys. Lett. 56 (1990) 1862-1864.

12) H. Geisler, K.O. Schweitz, J. Chevallier, J. Bottiger and K. Samwer: Philos. Mag. A 79 (1999) 485-500.

13) J. McKeown, A. Misra, H. Kung, R.G. Hoagland and M. Nastasi: Scr. Mater. 46 (2002) 593-598.

14) Y. Kaneko, Y. Mizuta, Y. Nishijima and S. Hashimoto: J. Mater. Sci. 40 (2005) 3231-3236.

15) A. Misra, J.P. Hirth and R.G. Hoagland: Acta Mater. 53 (2005) 48174824.

16) Y. Kaneko, H. Sakakibara and S. Hashimoto: J. Mater. Sci. 43 (2008) 3931-3937.

17) B. Ham and X. Zhang: Mater. Sci. Eng. A 528 (2011) 2028-2033.

18) Y. Chen, Y. Liu, C. Sun, K.Y. Yu, M. Song, H. Wang and X. Zhang: Acta Mater. 60 (2012) 6312-6321.

19) A.W. Ruff and D.S. Lashmore: Wear 151 (1991) 245-253.

20) S.K. Ghosh, P.K. Limaye, S. Bhattacharya, N.L. Soni and A.K. Grover: Surf. Coat. Tech. 201 (2007) 7441-7448.

21) T. Hattori, Y. Kaneko and S. Hashimoto: J. Mater. Sci. 43 (2008) 39233930 .

22) S. Yoshimoto, M. Yamasaki and Y. Kawamura: Mater. Trans. 47 (2006) 959-965.

23) M. Hirano, M. Yamasaki, K. Hagihara, K. Higashida and Y. Kawamura: Mater. Trans. 51 (2010) 1640-1647.

24) K. Hagihara, Z. Li, M. Yamasaki, Y. Kawamura and T. Nakano: Acta Mater. 163 (2019) 226-239.

25) A. Misra, J.P. Hirth and H. Kung: Philos. Mag. A 82 (2002) 29352951.

26) G. Nabiyouni, O.I. Kasyutich, C. Roy and W. Schwarzacher: J. Electrochem. Soc. 149 (2002) C218-C222.

27) L. Péter, J. Pádár, E. Kádár, Á. Cziráki, P. Sóki, L. Pogány and I. 
Bakonyi: Electrochim. Acta 52 (2007) 3813-3821.

28) R.C. Da Silva and W. Schwarzacher: J. Electrochem. Soc. 154 (2007) D88-D90.

29) Á. Cziráki, J.-G. Zheng, A. Michel, Z. Czigány, G. Nabiyouni, W. Schwarzacher, E. Tóth-Kádár and I. Bakonyi: Z. Metallk. 90 (1999) $278-283$.

30) G. Nabiyouni and W. Schwarzacher: J. Magn. Magn. Mater. 156 (1996) 355-356.

31) G. Nabiyouni and W. Schwarzacher: J. Magn. Magn. Mater. 198-199
(1999) 116-118

32) O.I. Kasyutich, W. Schwarzacher, V.M. Fedosyuk, P.A. Laskarzhevskiy and A.I. Masliy: J. Electrochem. Soc. 147 (2000) 2964-2968.

33) Y. Kaneko, T. Sanda and S. Hashimoto: Adv. Mater. Res. 26-28 (2007) 1321-1324.

34) F. Ebrahimi, A.J. Liscano, D. Kong and V. Krishnamoorthy: Philos. Mag. 83 (2003) 457-476.

35) A.J.E. Foreman and M.J. Makin: Philos. Mag. 14 (1966) 911-924. 